WORLD VIEW

\title{
The social and family dynamics behind the uptake of cataract surgery: findings from Kilimanjaro Region, Tanzania
}

\author{
R Geneau, S Lewallen, A Bronsard, I Paul, P Courtright
}

Br J Ophthalmol 2005;89:1399-1402. doi: 10.1136/bjo.2005.075572

See end of article for authors' affiliations

......................

Correspondence to:

Dr Robert Geneau,

Kilimanjaro Centre for

Community

Ophthalmology, Tumaini

University/KCMC, PO Box

2254, Moshi, Tanzania;

rgeneau@scohs.on.ca

Accepted for publication 1 August 2005

\begin{abstract}
Aims: To describe and understand better the barriers that elderly cataract patients in Kilimanjaro region (Tanzania) experience at the family level in order to access surgery.

Methods: A phenomenological study carried out in the catchment area of a teaching hospital in Kilimanjaro Region. 60 semi-structured interviews were conducted with patients and ex-cataract patients. Results: The perceived need for sight and for surgery appears partly socially constructed at the family level. It was found that women were less likely to express a need for sight for fear of being seen as a burden. Furthermore, young heads of family are more inclined to support old men than old women. The consensus is that asking children for help can be difficult. Going for cataract surgery must be seen as a social process where elderly patients might have to wait or negotiate support for weeks, months, or even years.

Conclusions: Eye programmes must promote the benefits of cataract surgery to all family members, not just to the patient. A changing social climate, changing expectations of vision, and evolving cost sharing systems will have significant, sometimes contradictory, impacts on use of eye care services. Strategies for reaching those without access to financial resources need to be strengthened.
\end{abstract}

$\mathrm{C}$ ataract is the leading cause of avoidable blindness in developing countries. ${ }^{1}$ The situation in Tanzania is no exception with cataract surgical rates across the different regions all below the WHO Vision 2020 target. In Kilimanjaro Region, the cataract surgical rate (number of cataract surgeries per million population) went from 375 in 2001 (authors' data) to 1165 in 2004, largely as a result of a new price for intraocular lens (IOL) surgery (from \$30 to \$15) and expansion of community based activities. ${ }^{2}$ Generally, only one third of the patients having cataract surgery in Kilimanjaro Region are blind $(<3 / 60$ in the better eye); another third have "normal vision" ( $\geqslant 6 / 18$ in the better eye). Yet, there are elderly people still blind and in need of surgery in Kilimanjaro Region despite improved access to a large and well equipped tertiary and teaching hospital (Kilimanjaro Christian Medical Centre, KCMC).

Financial, attitudinal, and socio-organisational barriers are the most common reasons given to explain the backlog of cataract patients in need of surgery in Africa. ${ }^{3}$ The direct and indirect costs of a cataract operation, which vary tremendously between and within African countries, are reported as a barrier in several papers, ${ }^{4}$ but some studies dispute cost as the most important factor preventing the uptake of surgery. In rural South Africa, fear of surgery and a low perceived need for better sight were found to be more important barriers. ${ }^{5}$ The perceived lack of availability of eye care services close to the communities is also reported as a barrier. ${ }^{6}$ Finally, lack of social support may prevent uptake of surgery by cataract patients. In the literature, this is described as the difficulty of finding an escort or, for women cataract patients, obtaining the permission of the husband. ${ }^{7}$ Family involvement in the health care of older adults is common but it remains an underexplored area of study. ${ }^{8}$ There have been no qualitative studies in Africa describing the decision making processes at the family level in relation to the uptake of cataract surgery. The objective of our study was to understand how family dynamics can influence the illness experience and therapeutic itinerary of older cataract patients in Kilimanjaro Region.

\section{METHODS}

This is a qualitative study ${ }^{9}$ describing the experiences of elderly patients who were told by an eye care specialist in May 2002, during a population based survey conducted in rural areas of Hai District (Kilimanjaro Region), that they could benefit from cataract surgery. We conducted 60 semistructured interviews (60-90 minutes each) between October 2002 and December 2004. Our respondents, described in table 1, are from the following tribes: Chagga (26), Masaai (18), Pare (10), Meru (two), Nymanwezi (one), and Mnyiramba (one). We also used the survey's data to purposefully select respondents with contrasting characteristics in relation to sex, laterality (unilateral or bilateral), and whether they had access to surgery. The interviews were conducted at the patients' home in Kiswahili or Kimasaai and translated into English. The interview transcripts were coded and analysed with the support of a qualitative data analysis software (N6). Ethical approval for the study was obtained from Tumaini University and informed consent was requested before interview.

\section{RESULTS}

Our results are presented in two sections: (1) the perceived need for sight and for surgery in its familial and social context, and (2) the family relations involved in mobilising the resources for surgery. We are focusing on the stories and experiences of the "typical" cataract patients in our samplethose from a rural household who have experienced a delay before going for surgery or who were still trying to access surgery at the time of the interview.

Abbreviations: IOL, intraocular lens; KCMC, Kilimanjaro Christian Medical Centre 


\begin{tabular}{|c|c|c|c|c|c|}
\hline \multirow[b]{2}{*}{ Cataract status } & \multicolumn{2}{|c|}{ Sex } & \multicolumn{3}{|c|}{ Age (years) } \\
\hline & $M$ & $\mathbf{F}$ & $\leqslant 60$ & $61-69$ & $\geqslant 70$ \\
\hline \multicolumn{6}{|l|}{ Unilateral } \\
\hline Operated & 3 & 4 & 1 & 6 & 0 \\
\hline Not operated & 6 & 7 & 1 & 6 & 6 \\
\hline \multicolumn{6}{|l|}{ Bilateral } \\
\hline Operated* & 11 & 7 & 5 & 10 & 3 \\
\hline Not operated & 7 & 15 & 2 & 6 & 14 \\
\hline Subtotal & 27 & 33 & 9 & 28 & 23 \\
\hline Total & 60 & & & & \\
\hline
\end{tabular}

\section{The perceived need for sight and for surgery in its} familial and social context

Among respondents with severe visual impairment, only those still physically capable of performing agricultural activities expressed a strong need for sight. Among respondents, "severe" was defined at the level of hand motion vision or when daily activities were no longer possible. Having one "good eye" was perceived to be sufficient and those with unilateral cataract were less likely to express a need for surgery to family members:

- "I actually see it is a disturbance to go for one eye operation only." (\#11)

The perceived need for sight partly depends on socially constructed expectations about work and quality of life at the age of 50 and over. The dimensions of quality of life mentioned by the interviewees were related to physical mobility, social interactions and financial autonomy. Our respondents reported that these dimensions all influence to various degrees their level of self esteem. In turn, this can affect if and how they will express a need for better sight and cataract surgery to family members. Our results indicate that men express more strongly than women a need for better sight. Women were more likely than men to hide from their children the fact they needed surgery while men tended to disclose it immediately to family. Women were more likely than men to be afraid of being seen as a "burden" on their children and, if blind, to experience a feeling of "shame" about receiving help for basic needs:

- "I feel very embarrassed (...) you must depend on someone just, like a little kid." (\#38)

We found complex relations between sight, self esteem, and socially determined roles and expectations. The result is that some women with severe visual impairment try to carry on with their routines through "adversity" instead of emphasising to their relatives their felt need for sight. Some relatives suggested that it is more important for an old man to "see" and be independent than it is for an old woman. Older men are still expected to have an important role in their community while older women tend to live in a "smaller" world, both geographically and socially.

The interviews also clearly showed that expressing the need for better sight does not necessarily imply willingness to go for cataract surgery, regardless of cost. For example, patients often elect to try traditional medicine first, following the advice of a family member. In some communities, cataract surgery is perceived as a direct cause of mortality since some patients die, as a result of ageing, within a few years after the operation. This belief makes it difficult for cataract patients to convince family members to provide the social and financial support needed for the surgery. Two of the six patients who paid for the operation themselves had to leave home under false pretences because their children perceived the operation as being too dangerous. However, in one case, it was actually the children who took their mother, almost manu militari, for cataract surgery. Overall, our data indicate that the perceived quality of services by cataract patients can trigger a positive or negative domino effect in terms of uptake of surgery at the community level.

\section{Family relations involved in the mobilisation of resources for surgery}

For the majority of respondents (54/60), most or all of the money for surgery and the associated expenses (food, transport) must come from various family members. Indeed, only six out of the 25 operated patients could cover those costs without help from relatives; all 35 non-operated patients mentioned that they could not pay by themselves. Therefore, the process of "paying" for surgery concerns several people apart from the patient himself and is inextricably linked to family relations. Patients must be willing to adopt a "sick role" and, in many cases, be proactive and persistent in mobilising the social and financial support for cataract surgery.

Women were less likely than men to ask for support. Several women cataract patients, especially widows, decided not to tell anyone in their family that cataract surgery had been recommended by a doctor:

- "The truth is, I didn't tell him (my son) because it was very difficult to ask (...) because I know that he is poor (...) I have just seen that money (to take me to hospital) will be a problem (...)." (\# 5)

- "I didn't seek help from any of the children, but it is not that much easy to get help from children as life is also very tough for everyone and children are busy taking care of their own family even if we grow them up." (\#6)

Several married women reported that the husband's permission is required before going for surgery. However, men over the age of 65 often have little income of their own and they merely represent an intermediary between their wife (wives) and the children. They still must "negotiate" social and financial support, especially from children who are away from home:

- "He (oldest son) should come so that he could be around during the screening day and pay for the surgery (...) I could even tell a lie by saying that his mother is very sick and that she is about to die (...) then I am sure that he will come." (\#54)

Elderly cataract patients expect greater financial support from their sons than daughters since daughters often have little or no personal income or assets (like cattle or land). All tribes in Kilimanjaro are patrilineal and asking sons in law, or even sons, for a financial contribution appears to be a socially 
sensitive issue because of a changing intergenerational "contract":

- "As you know you can also have children but not all of them will call you 'baba' (father) nowadays so there are some who will leave you alone without any help." (\#3)

Even in the best case scenario-for example, having at least two working sons, the amount of money patients can legitimately ask from family members for medical treatments is limited by various factors. It depends on the income of each family member in kind and in cash, the number of children going to school, the number of people in the family with health problems, and the nature of the illness. Local definitions of health and illness are centred on pain and since cataract is not painful, other medical conditions are often given a higher priority. It is also difficult for families to cope with multiple episodes of medical care in a short span of time. When they know their children paid for other medical expenses recently, many elderly patients are reluctant to ask for help. The ability of family members to pay for cataract surgery is affected by the fact that income is seasonal and can vary enormously from one year to another. Younger adults have competing needs (house, clothes, school fees, etc) and those relying exclusively on agriculture must make decisions to meet the most "urgent" in the 4-6 weeks following the sale of their crops. The result is that many elderly cataract patients have to wait for financial support:

- "I normally ask for help during harvesting season but I have little hope about going for surgery this year." (\#26)

- "Well, we don't love ourselves, we usually ignore many things and we are tolerant somehow. Usually we do consider severe and painful cases. However, I am a widow, I'm not in pain and I have found no one to give me some money and to support me for cataract surgery." (\#36)

For many elderly cataract patients, going for surgery appears to require the proper alignment of several factors. Indeed, a less than average rainy season or multiple medical problems in the family can delay the decision to have surgery by months even for the patients with a high perceived need for sight and surgery. In addition, many patients are ready to place other family members' needs ahead of their own.

\section{DISCUSSION}

For many elderly cataract patients in Kilimanjaro Region, going for surgery is the result of a complex family process that can last several weeks, months, or sometimes years. This has important implications since people with severe visual impairment in developing countries may be stigmatised ${ }^{10}$ and more likely to suffer from depression and loneliness. ${ }^{11}$ Many elderly individuals in Kilimanjaro Region feel embarrassed or ashamed to ask for help but, on the other hand, the longer they wait the more dependent they become on family members for their most basic needs, which in turn exacerbates their feeling of worthlessness. Either way, they may feel "socially" handicapped. Some elderly cataract patients see more benefits in ignoring their need for sight and eye care compared to entering the socially negotiated process of being perceived as "ill" and mobilising resources at the family level. In other words, there is a "social" cost to pay in addition of the direct and indirect costs of cataract surgery. Our results showed that this is especially true for women and for men unable to work or with no assets to sell (cows, goats, etc). Overall, men cataract patients seek and receive more family support than women cataract patients. This study also supports the contention that the traditional authority of the elders in African societies is slowly eroding. ${ }^{12}$ Intergenerational relationships are changing. Studies in the field of social gerontology have shown that while positive sentiments may be present and frequently expressed in intergenerational relationships, functional solidarity-the degree to which financial assistance and service exchanges occur among family members-is not a given. ${ }^{13}{ }^{14}$ In Kilimanjaro Region, this is illustrated by the fact that young heads of household and elderly individuals themselves are now more inclined to prioritise the needs of younger family members. This (new) conception of "utility" in the decision making processes at the family level may be linked with the difficult economic conditions in Hai District where income is seasonal and fluctuating from one year to another. Still, some family features seem predictive of the uptake of surgery by elderly patients such as the presence of working sons with a regular source of income.

Overall, we estimate that, in Kilimanjaro Region, only one out of three cataracts is treated; the eye care needs of the elderly are not always met. The changing social climate and evolving cost recovery systems may leave some elderly people highly vulnerable and disadvantaged in terms of access to health and eye care services. At the same time, we observe (generally younger and still active) patients coming for surgery before blindness; these apparently contradictory findings indicate that the oldest age groups within the rural population have minimal access to services. From a programme perspective, we see at least two interconnected areas of improvement that could make the therapeutic itinerary of elderly cataract patients smoother. Firstly, we must be able to monitor and demonstrate improvements in quality of life from cataract surgery not just to the patients but also to their relatives. Secondly, there is need for (more) community based programmes that invest in support and counselling activities at the community level. The development of a community support system could become a powerful channel to influence social relationships at the family level and identify those patients who truly need external support. Since the development of sustainable eye care programmes currently involves cost sharing, there is a need to put more efforts into reliably identifying the most vulnerable and disadvantaged and designing practical schemes to support them.

\section{ACKNOWLEDGEMENTS}

This work was supported by a grant from the World Health Organization "Gender, Women and Health" Unit. Additional support was provided by the Seva Foundation and Seva Canada. We are grateful for the cooperation of the residents of Hai district of Kilimanjaro Region for participating in the interviews.

\section{Authors' affiliations}

R Geneau, S Lewallen, A Bronsard, I Paul, P Courtright, Kilimanjaro Centre for Community Ophthalmology, Tumaini University/KCMC, PO Box 2254, Moshi, Tanzania

Competing interests: none declared

\section{REFERENCES}

1 Pizzarello L, Abiose A, Ffytche T, et al. Vision 2020: the right to sight: a global initiative to eliminate avoidable blindness. Arch Ophthalmol 2004;122:615-20.

2 Lewallen S, Roberts $\mathrm{H}$, Hall A, et al. Increasing cataract surgery to meet Vision 2020 targets; experience from two rural programmes in rural east Africa. Br J Ophthalmol 2005;89:1237-40

3 Lewallen S, Courtright P. Blindness in Africa: present situation and future needs. Br J Ophthalmol 2001;85:897-903.

4 Melese M, Alemayehu W, Friedlander E, et al. Indirect costs associated with accessing eye care services as a barrier to service use in Ethiopia. Trop Med Int Health 2004;9:426-31.

5 Rotchford AP, Rotchford KM, Mthethwa LP, et al. Reasons for poor cataract surgery uptake-a qualitative study in rural South Africa. Trop Med Int Health 2002;7:288-92.

6 Johnson JG, Sen VG, Faal H. Barriers to the uptake of cataract surgery. Trop Doctor 2000;7:218-20. 
7 Courtright $\mathbf{P}$, Kanjaloti S, Lewallen S. Barriers to acceptance of catarac surgery among patients presenting to district hospitals in rural Malawi. Trop Geogr Med 1995;47:15-18.

8 Roberto K. Making critical health care decisions for older adults: consensus among family members. Family Relations 1999:48:167-75.

9 Creswell JW. Qualitative inquiry and research design: choosing among five traditions. Thousand Oaks, CA: Sage Publications, 1998.

10 Sentumbwe N. Sighted lovers and blind husbands: experiences of blind women in Uganda. In: Ingstad B, Reynolds-Whyte S, eds. Disability and culture. Berkeley, CA: University of California Press, 1995.
11 Tsai S, Cheng $\mathrm{C}, \mathrm{Hsu}$ W et al. Association between visual impairment and depression in the elderly. J Formos Med Assoc 2003; 102:86-90.

12 Devisch R, Makoni S, Stroeken K. African gerontology: critical models, future directions. In: Makoni S, Stroeken K, eds. Ageing in Africa: sociolinguistic and anthropological approaches. Hampshire: Ashgate, 2002.

13 Bengtson VL, Schrader SS. Parent-child relations. In: Mangen DJ, Peterson WA, eds. Research instruments in social gerontology. Vol 2. Minneapolis: University of Minnesota Press, 1982.

14 Hammerström G. The construct of intergenerational solidarity in a lineage perspective: a discussion on underlying theoritical assumptions. J Aging Studies 2005; 19:33-51.

\section{Video reports}

To view the video reports in full visit our website www. bjophthalmol.com and click on the link to the video reports.

- Magnet-assisted pars plana vitrectomy for giant metallic intraocular foreign body. $R$ Jorge, RA Costa, JC Castro, RC Siqueira

- Suture of a Subluxated Posterior Chamber Lens within the Capsular Bag. LE Fernández de Castro, KD Solomon

- Ocular Onchocerciasis: Anterior Chamber Microfilariae. WJ Flynn, HD Dillon

- Zero Phaco Microincision Cataract Surgey: The Hacc Technique. K Vaitheeswaran, $S$ Gars, R Grover, M Nadar, S Sharma

- The presenting features of multiple sclerosis. VJM Barrett, J Walker, JS Elton

- Removal of INTACS: Stepped surgical complexity demonstrated with three cases. L Ilari, J C McAlister, D S Gartry

- The Nuclear Slide: A novel approach for unleashing the potential of the hydrodissection wave. A Naseri

- Giant pleomorphic adenoma of the lacrimal gland: pre- and post-operative function. A Jain, V I Nehru, U N Saikia, C E E Reddy

- Limbal-sparing lamellar keratoplasty. S L Watson, S Rauz, J Dart 